\section{Symptom burden in transplant-ineligible patients with newly diagnosed multiple myeloma: a popula- tion-based cohort study}

Multiple myeloma (MM), a neoplasm characterized by the clonal proliferation of malignant plasma cells, is associated with major morbidity and mortality. The median age at diagnosis is 70 years, making $\mathrm{MM}$ a disease of older adults. While much progress has been made in the therapeutics for newly-diagnosed multiple myeloma (NDMM) patients, including transplant-ineligible patients, MM remains an incurable malignancy. Both the disease of MM itself, as well as the treatments initiated, likely impact patients' quality of life and their burden of symptoms. To date, there has been no large population study conducted in adults with NDMM, specifically transplant-ineligible patients, examining the effect of symptom burden over time and associated factors.

In 2007 , as part of an initiative to improve symptom management, routine prospective collection of a patientreported outcome, the Edmonton Symptom Assessment System (ESAS) score, during all outpatient cancer clinic visits was started in Ontario, Canada. The ESAS is a validated and reliable patient-reported outcome tool that is used to assess common cancer-associated symptoms. ${ }^{1}$ It consists of nine symptoms, namely tiredness, impaired well-being, pain, drowsiness, loss of appetite, anxiety, shortness of breath, depression and nausea, which are scored by the patients on a numerical rating scale from 0 (no symptoms) to 10 (worst possible symptoms). We conducted a longitudinal study of ESAS data in order to examine symptom trajectory and determine factors associated with moderate to severe symptoms in the first year following diagnosis among transplant-ineligible adults with NDMM receiving treatment between 2007-2018.

Multiple administrative healthcare databases in the universal, single-payer, publicly funded system in Ontario, Canada were linked using a unique encrypted patient identifier and analyzed at ICES (formerly known as the Institute for Clinical Evaluative Sciences). ICES is an independent, non-profit research institute whose legal status allows it to collect and analyze healthcare and demographic data without consent for health system evaluation and improvement. The study was approved by the ethics committee of McMaster University and followed data confidentiality and privacy guidelines of ICES.

All adults (age $\geq 18$ years) with a new diagnosis of MM (International Classification of Diseases for Oncology, $3^{\text {rd }}$ Edition, histology code 9732) between January 2007 and December 2018 were identified. Patients' demographics (age, sex) were extracted. Baseline co-morbidities were recorded using the modified Charlson-Deyo Comorbidity Index (CCI) within 1 year prior to the date of diagnosis. ${ }^{2}$ Socioeconomic status was determined using a validated modified Ontario Marginalization Index. ${ }^{3}$ Myelomarelated end-organ damage was defined as previously described by Fiala et al. ${ }^{4}$ Treatment center (non-teaching vs. teaching) was defined as the center in which the patient first received $\mathrm{MM}$ treatment. Treatment receipt was defined as not having received a transplant but having received therapy with one or more of the following agents: oral cyclophosphamide/melphalan (often used in combination with steroids) or novel agents (thalidomide, lenalidomide or bortezomib often used in combination as thalidomide/melphalan/prednisone, lenalidomide/dexamethasone, bortezomib/melphalan/prednisone or cyclophosphamide/bortezomib/dexamethasone) within
Table 1. Characteristics of multiple myeloma patients who reported at least one Edmonton Symptom Assessment System score in the first 12 months following diagnosis.

\begin{tabular}{|c|c|}
\hline Characteristics & $(\mathrm{N}=2876)$ \\
\hline Age, years; median (IQR) & $74(70-80)$ \\
\hline Male; $\mathrm{n}(\%)$ & $1,649(57.3)$ \\
\hline $\begin{array}{l}\text { Geographic region; } n(\%) \\
\text { Urban } \\
\text { Rural }\end{array}$ & $\begin{array}{c}2,473(86.0) \\
403(14.0)\end{array}$ \\
\hline Socioeconomic status, poor; n (\%) & $464(16.1)$ \\
\hline $\begin{array}{l}\text { Charlson Co-morbidity Index; } n(\%) \\
\quad \leq 1 \\
\geq 2\end{array}$ & $\begin{array}{l}2,478(86.2) \\
398(13.8)\end{array}$ \\
\hline $\begin{array}{l}\text { Year of diagnosis; n (\%) } \\
2007-2012 \\
2013-2018\end{array}$ & $\begin{array}{c}953(33.1) \\
1,923(66.9)\end{array}$ \\
\hline $\begin{array}{l}\text { Myeloma end-organ damage*; n (\%) } \\
\text { Anemia } \\
\text { Hypercalcemia } \\
\text { Bone disease } \\
\text { Renal failure }\end{array}$ & $\begin{array}{l}911(31.7) \\
130(4.5) \\
304(10.6) \\
752(26.2)\end{array}$ \\
\hline $\begin{array}{l}\text { Time from diagnosis to treatment, } \\
\text { days; median (IQR) }\end{array}$ & $39(20-87)$ \\
\hline $\begin{array}{l}\text { Time from diagnosis to first recorded ESAS score; } \\
\text { median (IQR) }\end{array}$ & $35(14-79)$ \\
\hline Hospital type; $n(\%)$ & \\
\hline Teaching & $676(23.5)$ \\
\hline Non-teaching & $2,200(76.5)$ \\
\hline $\begin{array}{l}\text { Novel agents; } \mathrm{n}(\%) \\
\text { Proteasome inhibitor } \\
\text { Immunomodulatory agent }\end{array}$ & $\begin{array}{c}2,146(74.6) \\
688(23.9)\end{array}$ \\
\hline Patients alive at 1 year; $\mathrm{n}(\%)$ & 2,349 (81.7) \\
\hline
\end{tabular}

*Patients could have more than one 'CRAB' feature. IQR: interquartile range; ESAS Edmonton Symptom Assessment System.

1 year of diagnosis; the above anti-myeloma drugs encompass all funded cancer drugs available to patients during the study period.

Symptoms were assessed using the ESAS score which consists of the nine symptoms described previously. We considered ESAS scores of $\geq 4$ (moderate or severe) as being clinically relevant because they have been previously shown to identify a clinically significant burden. ${ }^{5}$ For the final cohort creation, only transplant-ineligible patients who received MM treatment as defined above and reported at least one ESAS assessment in the 12 months following the date of diagnosis were included. All analyses were conducted using the Statistical Analysis System (SAS version 9.4).

A total of 4,610 transplant-ineligible patients who received treatment for NDMM were identified, of whom $2,876(62.3 \%)$ completed at least one ESAS assessment following diagnosis and were included in the final cohort. In this final cohort, a total of 27,701 unique ESAS assessments were captured. Patients recorded a median of 15 ESAS assessments in the first year (interquartile range [IOR] 9-29). The baseline characteristics of the cohort are detailed in Table 1.

The trajectory of moderate to severe symptoms in each month following diagnosis is shown in Figure 1. For most symptoms, a high proportion of the cohort reported moderate to severe symptoms at diagnosis, with tiredness $(64 \%)$ and impaired well-being $(60 \%)$ being among 
A

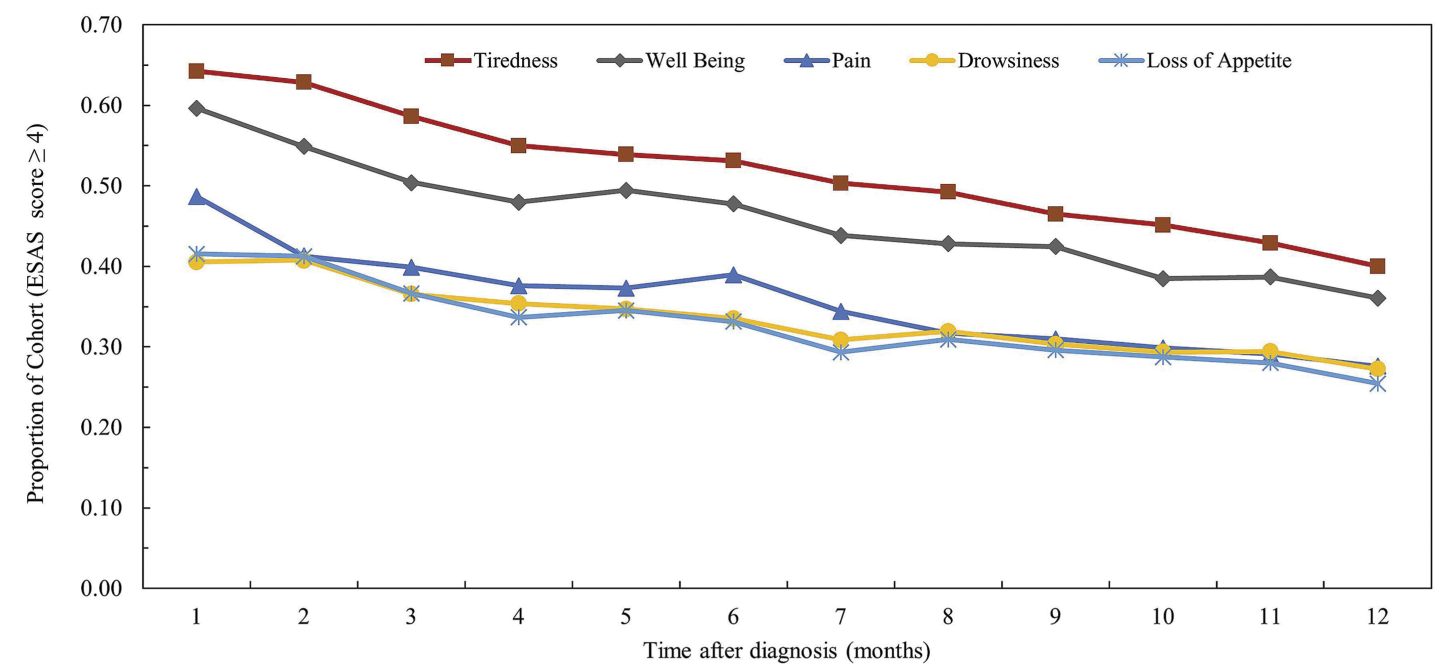

B

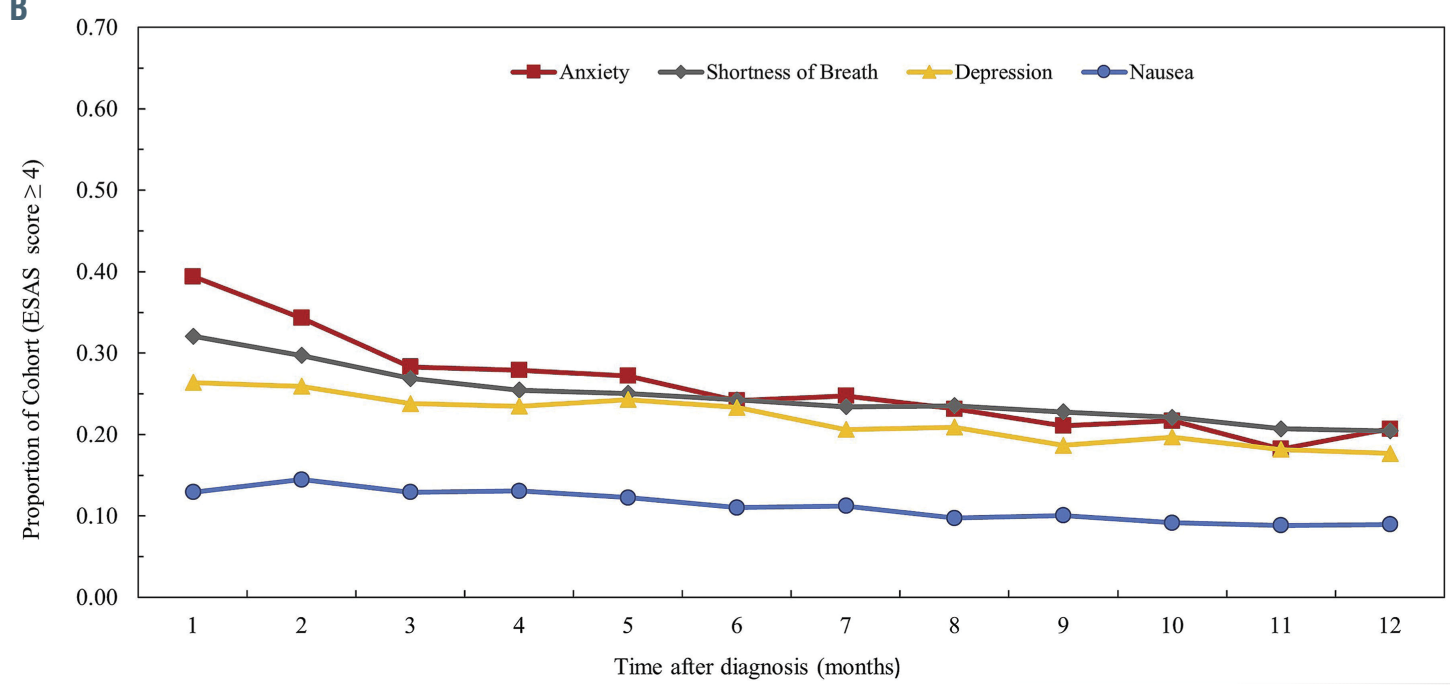

Figure 1. Trajectory of symptom burden in patients with newly diagnosed multiple myeloma. Proportion of the cohort reporting moderate-to-severe Edmonton Symptom Assessment System (ESAS) scores $\geq 4$ for (A) tiredness, well-being, pain, drowsiness and loss of appetite and (B) anxiety, shortness of breath, depression and nausea, by month following diagnosis.

the most prevalent and nausea being the least prevalent $(13 \%)$. Most symptoms decreased over the first year, with the largest decline happening in the first 3 months. One year following diagnosis, there continued to be a substantial burden of symptoms, with over $25 \%$ of the cohort reporting moderate-severe levels of each of the following symptoms: tiredness, impaired well-being, pain, drowsiness and loss of appetite. Additionally, whereas physical symptoms such as pain improved over time, psychosocial symptoms of anxiety/depression showed minimal improvement with generally flat scores.

The odds of reporting moderate to severe symptoms during the first year are listed in Table 2 with a higher odds ratio for a co-variate being 'worse' for each specified symptom. Increasing age was associated with a slightly lower burden of pain, depression and nausea with an odds ratio that was borderline at 0.98 . Female sex was associated with a 1.19 to 1.59 higher odds of reporting moderate to severe symptoms for all categories except shortness of breath. An urban geographic location was associated with higher anxiety and nausea. Socioeconomic status did not have an impact on most symptoms except for tiredness. Increased co-morbidity status did not show any clear correlation with increased symptoms. A more recent year of diagnosis was associated with slightly lower odds of pain, loss of appetite and nausea. Receiving treatment at a non-teaching hospital was associated with higher odds of reporting pain and depression. Myeloma-related end-organ damage, specifically bone disease, was associated with higher symptom burden; the effect size ranging from 1.52 to 2.65 times for impaired well-being and pain respectively.

In summary, our study demonstrates that transplantineligible patients with NDMM experience a substantial burden of symptoms following diagnosis. From a patient's perspective, knowledge of these symptoms and how they change over time may enhance communication regarding expected trajectory and informed shared decision-making. From the oncology team's perspective, understanding the considerable burden of symptoms 
Table 2. The odds ratio of reporting moderate to severe Edmonton Symptoms Assessment System score $(\geq 4)$ during the first year following diagnosis using multivariable logistic regression."

\begin{tabular}{|c|c|c|c|c|c|c|c|c|c|}
\hline & Tiredness & $\begin{array}{l}\text { Well } \\
\text { being }\end{array}$ & Pain & Drowsiness & $\begin{array}{l}\text { Loss } \\
\text { of appetite }\end{array}$ & Anxiety & $\begin{array}{l}\text { Shortness } \\
\text { of breath }\end{array}$ & Depression & Nausea \\
\hline $\begin{array}{l}\text { Age } \\
\text { (per year increase) }\end{array}$ & $\begin{array}{c}1.01 \\
(0.99-1.02)\end{array}$ & $\begin{array}{c}1.00 \\
(0.99-1.02)\end{array}$ & $\begin{array}{c}0.98 \\
(0.98-0.99)\end{array}$ & $\begin{array}{c}0.99 \\
(0.99-1.01)\end{array}$ & $\begin{array}{c}1.00 \\
(0.99-1.01)\end{array}$ & $\begin{array}{c}0.99 \\
(0.98-1.00)\end{array}$ & $\begin{array}{c}1.00 \\
(0.99-1.01)\end{array}$ & $\begin{array}{c}0.98 \\
(0.87-0.99)\end{array}$ & $\begin{array}{c}0.98 \\
(0.97-0.99)\end{array}$ \\
\hline $\begin{array}{l}\text { Sex } \\
\text { (female vs. male) }\end{array}$ & $\begin{array}{c}1.36 \\
(1.11-1.68)\end{array}$ & $\begin{array}{c}1.35 \\
(1.12-1.63)\end{array}$ & $\begin{array}{c}1.28 \\
(1.09-1.52)\end{array}$ & $\begin{array}{c}1.19 \\
(1.02-1.39)\end{array}$ & $\begin{array}{c}1.43 \\
(1.22-1.67)\end{array}$ & $\begin{array}{c}1.59 \\
(1.35-1.85)\end{array}$ & $\begin{array}{c}0.92 \\
(0.79-1.06)\end{array}$ & $\begin{array}{c}1.32 \\
(1.12-1.52)\end{array}$ & $\begin{array}{c}1.56 \\
(1.33-1.85)\end{array}$ \\
\hline $\begin{array}{l}\text { Location } \\
\text { (urban vs. rural) }\end{array}$ & $\begin{array}{c}0.85 \\
(0.63-1.15)\end{array}$ & $\begin{array}{c}0.99 \\
(0.76-1.30)\end{array}$ & $\begin{array}{c}1.00 \\
(0.79-1.27)\end{array}$ & $\begin{array}{c}0.96 \\
(0.76-1.20)\end{array}$ & $\begin{array}{c}1.04 \\
(0.83-1.32)\end{array}$ & $\begin{array}{c}1.29 \\
(1.05-1.61)\end{array}$ & $\begin{array}{c}0.99 \\
(0.79-1.22)\end{array}$ & $\begin{array}{c}1.06 \\
(0.85-1.32)\end{array}$ & $\begin{array}{c}1.35 \\
(1.02-1.72)\end{array}$ \\
\hline $\begin{array}{l}\text { SES } \\
\text { (poor vs. non-poor) }\end{array}$ & $\begin{array}{c}1.31 \\
(1.01-1.69)\end{array}$ & $\begin{array}{c}0.95 \\
(0.74-1.22)\end{array}$ & $\begin{array}{c}0.93 \\
(0.75-1.16)\end{array}$ & $\begin{array}{c}1.10 \\
(0.89-1.36)\end{array}$ & $\begin{array}{c}0.92 \\
(0.74-1.14)\end{array}$ & $\begin{array}{c}1.18 \\
(0.96-1.45)\end{array}$ & $\begin{array}{c}1.15 \\
(0.94-1.40)\end{array}$ & $\begin{array}{c}0.89 \\
(0.72-1.09)\end{array}$ & $\begin{array}{c}1.06 \\
(0.85-1.32)\end{array}$ \\
\hline $\begin{array}{l}\text { CCI } \\
(\geq 2 \text { vs. } \leq 1)\end{array}$ & $\begin{array}{c}1.20 \\
(0.88-1.64)\end{array}$ & $\begin{array}{c}1.09 \\
(0.83-1.44)\end{array}$ & $\begin{array}{c}1.02 \\
(0.80-1.29)\end{array}$ & $\begin{array}{c}1.20 \\
(0.95-1.51)\end{array}$ & $\begin{array}{c}1.02 \\
(0.81-1.29)\end{array}$ & $\begin{array}{c}1.02 \\
(0.82-1.28)\end{array}$ & $\begin{array}{c}1.10 \\
(0.89-1.37)\end{array}$ & $\begin{array}{c}1.02 \\
(0.81-1.27)\end{array}$ & $\begin{array}{c}1.07 \\
(0.85-1.36)\end{array}$ \\
\hline $\begin{array}{l}\text { Year of diagnosis } \\
\text { (per year increase) }\end{array}$ & $\begin{array}{c}0.98 \\
(0.94-1.01)\end{array}$ & $\begin{array}{c}0.97 \\
(0.94-1.01)\end{array}$ & $\begin{array}{c}0.96 \\
(0.93-0.99)\end{array}$ & $\begin{array}{c}0.99 \\
(0.96-1.02)\end{array}$ & $\begin{array}{c}0.92 \\
(0.89-0.95)\end{array}$ & $\begin{array}{c}0.97 \\
(0.95-1.00)\end{array}$ & $\begin{array}{c}0.99 \\
(0.97-1.02)\end{array}$ & $\begin{array}{c}0.99 \\
(0.87-1.02)\end{array}$ & $\begin{array}{c}0.95 \\
(0.92-0.98)\end{array}$ \\
\hline $\begin{array}{l}\text { Anemia } \\
\text { (yes vs. no) }\end{array}$ & $\begin{array}{c}1.05 \\
(0.84-1.31)\end{array}$ & $\begin{array}{c}1.05 \\
(0.86-1.28)\end{array}$ & $\begin{array}{c}0.96 \\
(0.81-1.14)\end{array}$ & $\begin{array}{c}1.00 \\
(0.84-1.18)\end{array}$ & $\begin{array}{c}0.95 \\
(0.80-1.13)\end{array}$ & $\begin{array}{c}1.23 \\
(1.05-1.45)\end{array}$ & $\begin{array}{c}1.19 \\
(1.01-1.40)\end{array}$ & $\begin{array}{c}1.11 \\
(0.95-1.31)\end{array}$ & $\begin{array}{c}0.99 \\
(0.83-1.18)\end{array}$ \\
\hline $\begin{array}{l}\text { Hypercalcemia } \\
\text { (yes vs. no) }\end{array}$ & $\begin{array}{c}1.86 \\
(0.98-3.53)\end{array}$ & $\begin{array}{c}1.10 \\
(0.68-1.78)\end{array}$ & $\begin{array}{c}1.64 \\
(1.06-2.54)\end{array}$ & $\begin{array}{c}1.36 \\
(0.90-2.04)\end{array}$ & $\begin{array}{c}1.25 \\
(0.83-1.88)\end{array}$ & $\begin{array}{c}1.14 \\
(0.79-1.66)\end{array}$ & $\begin{array}{c}1.10 \\
(0.76-1.58)\end{array}$ & $\begin{array}{c}1.35 \\
(0.94-1.96)\end{array}$ & $\begin{array}{c}1.18 \\
(0.81-1.73)\end{array}$ \\
\hline $\begin{array}{l}\text { Bone disease } \\
\text { (yes } v s . \text { no) }\end{array}$ & $\begin{array}{c}1.23 \\
(0.87-1.73)\end{array}$ & $\begin{array}{c}1.52 \\
(1.10-2.12)\end{array}$ & $\begin{array}{c}2.65 \\
(1.92-3.67)\end{array}$ & $\begin{array}{c}1.29 \\
(0.99-1.67)\end{array}$ & $\begin{array}{c}1.72 \\
(1.31-2.27)\end{array}$ & $\begin{array}{c}1.07 \\
(0.84-1.37)\end{array}$ & $\begin{array}{c}1.022 \\
(0.80-1.30)\end{array}$ & $\begin{array}{c}1.22 \\
(0.96-1.56)\end{array}$ & $\begin{array}{c}1.12 \\
(0.87-1.45)\end{array}$ \\
\hline $\begin{array}{l}\text { Renal Disease } \\
\text { (yes } v s . \text { no) }\end{array}$ & $\begin{array}{c}1.26 \\
(0.99-1.62)\end{array}$ & $\begin{array}{c}1.31 \\
(1.05-1.64)\end{array}$ & $\begin{array}{c}0.85 \\
(0.71-1.03)\end{array}$ & $\begin{array}{c}1.12 \\
(0.93-1.35)\end{array}$ & $\begin{array}{c}1.36 \\
(1.13-1.65)\end{array}$ & $\begin{array}{c}1.07 \\
(0.89-1.27)\end{array}$ & $\begin{array}{c}1.09 \\
(0.92-1.30)\end{array}$ & $\begin{array}{c}1.081 \\
(0.91-1.29)\end{array}$ & $\begin{array}{c}1.07 \\
(0.89-1.30)\end{array}$ \\
\hline $\begin{array}{l}\text { Hospital } \\
\text { (Non-teaching vs. } \\
\text { teaching) }\end{array}$ & $\begin{array}{c}0.91 \\
(0.72-1.17)\end{array}$ & $\begin{array}{c}1.09 \\
(0.88-1.35)\end{array}$ & $\begin{array}{c}1.27 \\
(1.05-1.54)\end{array}$ & $\begin{array}{c}0.93 \\
(0.88-1.11)\end{array}$ & $\begin{array}{c}0.94 \\
(0.78-1.14)\end{array}$ & $\begin{array}{c}1.11 \\
(0.93-1.33)\end{array}$ & $\begin{array}{c}1.05 \\
(0.88-1.27)\end{array}$ & $\begin{array}{c}1.23 \\
(1.03-1.47)\end{array}$ & $\begin{array}{c}1.08 \\
(0.88-1.30)\end{array}$ \\
\hline $\begin{array}{l}\text { Novel drugs } \\
\text { (yes vs. no) }\end{array}$ & $\begin{array}{c}1.01 \\
(0.73-1.39)\end{array}$ & $\begin{array}{c}0.96 \\
(0.71-1.30)\end{array}$ & $\begin{array}{c}1.20 \\
(0.93-1.55)\end{array}$ & $\begin{array}{c}0.94 \\
(0.73-1.20)\end{array}$ & $\begin{array}{c}0.96 \\
(0.75-1.25)\end{array}$ & $\begin{array}{c}0.99 \\
(0.78-1.26)\end{array}$ & $\begin{array}{c}0.88 \\
(0.69-1.11)\end{array}$ & $\begin{array}{c}0.95 \\
(0.75-1.21)\end{array}$ & $\begin{array}{c}1.12 \\
(0.87-1.45)\end{array}$ \\
\hline
\end{tabular}

"Data are presented as odds ratios (95\% confidence interval).A higher odds ratio is 'worse', indicating that the covariate is associated with a higher odds of reporting moderate to severe symptom. Bold indicates statistically significant values $(P<0.05)$. SES: socioeconomic status; CCI: Charlson Comorbidity Index.

both at diagnosis and over time may be an essential first step in incorporating multidisciplinary teams, with a specific focus on managing psychosocial symptoms, which are known to be often unaddressed by oncology teams. ${ }^{6}$

Several patients' characteristics were identified in our study as being associated with an increased odds of experiencing high symptom burden. Although increasing age was associated with a slight decrease in symptom burden, given the minimal change in odds ratio, the clinical impact of this is unknown. Compared to males, females had a higher symptom burden for nearly all recorded symptoms in our study, similarly to previously published literature in oncology which also reported sex differences in symptom burden and quality of life. ${ }^{7,8}$ Additionally, although increased co-morbidities has been previously shown to be correlated with a higher symptoms burden, we did not detect a statistically significant relationship in our retrospective study and future prospective studies are needed for further investigation. Non-teaching hospital was associated with higher rates of pain and depression and although the exact reason cannot be determined from our data, clinical outcomes are known to be different between teaching and non-teaching sites. ${ }^{10}$ Lastly, while the majority of patients in our study were taking novel drugs, these drugs were not associated with a decrease in symptom burden, suggesting that symptom management may require both effective anti-myeloma therapy as well as optimal supportive care services.

Comparison of our results to those of other studies on transplant-ineligible patients is difficult due to the hetero- geneous populations included which encompass newlydiagnosed, relapsed as well as palliative patients. ${ }^{11,12}$ Despite these differences, the findings of our study are consistent with the results of a systematic review which also showed that severe fatigue and pain were common symptoms, with the pooled prevalence reaching more than $40 \%$ with anxiety/depression present in nearly $25 \%$ of the patients. ${ }^{13}$

A major strength of our study is that it is the largest, longitudinal study done on symptom burden among this group of patients using patient-reported outcomes. Our study utilizes real-world data with a focus on older adults with $\mathrm{MM}$ who are under-represented in clinical trials. ${ }^{14}$ Our study has several limitations. Our administrative database does not contain myeloma-specific variables, such as stage, response, or frailty status, which may be associated with symptom burden. Additionally, we did not capture symptoms during specific lines of treatment which may also be important as shown in a recent prospective study in which quality of life deteriorated with increasing line of treatment. ${ }^{15}$ The myeloma-defining 'CRAB' features may also be under-reported or overreported compared to those in prospectively conducted studies $^{16}$ because of the limitations of diagnosis and billing codes in the administrative database. Similarly, retrospective collection of co-morbidities may also have led to under-reporting as noted in previous studiess. ${ }^{17}$ ESAS scores were only recorded during outpatient visits and potentially severe symptoms during hospital admissions may have been missed in our study. While the ESAS 
has been validated for general cancer symptoms, we were not able to capture symptoms specifically related to $\mathrm{MM}$ or the impact of symptom burden on the disruption of functional and social activities of the patients or their caregivers.

In conclusion, transplant-ineligible patients with MM experience a substantial burden of symptoms in the first year following diagnosis. Future prospective studies both in clinical trials and in real-world patients are needed to further evaluate factors associated with high symptom burden longitudinally while simultaneously evaluating interventional supportive care strategies to alleviate this burden.

Hira S. Mian, ${ }^{1}$ Gregory R. Pond, ${ }^{2}$ Tanya M. Wildes, ${ }^{3}$ Branavan Sivapathasundaram, Jonathan Sussman ${ }^{1}$ and Hsien Seow

IJuravinski Cancer Center, Department of Oncology, McMaster University, Hamilton, Ontario, Canada: ${ }^{2}$ McMaster University, Hamilton, Ontario, Canada and ${ }^{3}$ Washington University School of Medicine, St. Louis, MO, USA

Correspondence: HIRA S. MIAN - hira.mian@medportal.ca

doi:10.3324/haematol.2020.267757

Received: September 11, 2020.

Accepted: December 10, 2020.

Pre-published: December 23, 2020.

Disclosures: HSM has received consultancy fees and/or honoraria from Celgene, Takeda, Janssen, Amgen, and Sanofi; GRP has a close family member who is employed by Roche Canada, and who owns Roche Canada stock; he has also received consultancy fees from AstraZeneca and an honorarium from Takeda. TMW reports having received research funding from Janssen and is a consultant for Carevive Systems and Seattle Genetics. BS, JS and HS have no conflicts of interest to disclose.

Contributions: HSM, GRP, HS and JS were responsible for the conception and design of the study; BS and HSM collected the data; $H S M, G R P, B S, T M W, H S$, and JS analyzed and interpreted the data. All authors were involved in writing the manuscript and approved its final version.

Acknowledgments: the authors would like to thank Dr. Mark Levine for manuscript revision. Parts of the material are based on data and/or information compiled and provided by the Canadian Institute for Health Information (CIHI). However, the analyses, conclusions, opinions and statements expressed in the material are those of the authors, and not necessarily those of CIHI. We acknowledge Cancer Care Ontario for access to the Ontario Cancer Registry (OCR), Cancer Activity Level Reporting (ALR), Symptom Management Database (ESAS) and The New Drug Funding Program (NDFP). We thank IQVIA Solutions Canada Inc. for the use of their Drug Information Database.

Funding: this investigation was supported by a grant from the Juravinski Cancer Centre Foundation and Myeloma Canada. The study was supported by ICES, which is funded by an annual grant from the Ontario Ministry of Health and Long-Term Care (MOHLTC). The opinions, results and conclusions reported in this arti- cle are those of the authors and are independent of the funding sources. No endorsement by ICES or the Ontario MOHLTC is intended or should be inferred.

\section{References}

1. Bruera E, Kuehn N, Miller MJ, Selmser P, Macmillan K. The Edmonton Symptom Assessment System (ESAS): a simple method for the assessment of palliative care patients. J Palliat Care. 1991;7(2):6-9.

2. Deyo RA, Cherkin DC, Ciol MA. Adapting a clinical comorbidity index for use with ICD-9-CM administrative databases. J Clin Epidemiol. 1992;45(6):613-619.

3. Matheson FI, White HL, Moineddin R, Dunn JR, Glazier RH Neighbourhood chronic stress and gender inequalities in hypertension among Canadian adults: a multilevel analysis. J Epidemiol Community Health. 2010;64(8):705-713.

4. Fiala MA, Dukeman J, Tuchman SA, Keller M, Vij R, Wildes TM. Development of an algorithm to distinguish smoldering versus symptomatic multiple myeloma in claims-based data sets. JCO Clin Cancer Inform. 2017;1:CCI.17.00089.

5. Selby D, Cascella A, Gardiner K, et al. A single set of numerical cutpoints to define moderate and severe symptoms for the Edmonton Symptom Assessment System. J Pain Symptom Manage. 2010;39(2):241-249.

6. Hallet J, Davis LE, Isenberg-Grzeda E, et al. Gaps in the management of depression symptoms following cancer diagnosis: a populationbased analysis of prospective patient-reported outcomes. Oncologist. 2020;25(7):e1098-e1108.

7. Laghousi D, Jafari E, Nikbakht H, Nasiri B, Shamshirgaran M, Aminisani N. Gender differences in health-related quality of life among patients with colorectal cancer. J Gastrointest Oncol. 2019;10(3):453-461.

8. Cheung WY, Le LW, Gagliese L, Zimmermann C. Age and gender differences in symptom intensity and symptom clusters among patients with metastatic cancer. Support Care Cancer. 2011;19(3):417-423

9. Ritchie CS, Zhao F, Patel K, et al. Association between patients' perception of the comorbidity burden and symptoms in outpatients with common solid tumors. Cancer. 2017;123(19):3835-3842.

10. Burke LG, Frakt AB, Khullar D, Orav EJ, Jha AK. Association between teaching status and mortality in US hospitals. JAMA. 2017;317(20):2105-2113.

11. Ramsenthaler C, Gao W, Siegert RJ, Edmonds PM, Schey SA Higginson IJ. Symptoms and anxiety predict declining health-related quality of life in multiple myeloma: a prospective, multi-centre longitudinal study. Palliat Med. 2019;33(5):541-551.

12. Mols F, Oerlemans S, Vos AH, et al. Health-related quality of life and disease-specific complaints among multiple myeloma patients up to 10 yr after diagnosis: results from a population-based study using the PROFILES registry. Eur J Haematol. 2012;89(4):311-319.

13. Ramsenthaler C, Kane P, Gao W, et al. Prevalence of symptoms in patients with multiple myeloma: a systematic review and metaanalysis. Eur J Haematol. 2016;97(5):416-429.

14. Duma N, Azam T, Riaz IB, Gonzalez-Velez M, Ailawadhi S, Go R. Representation of minorities and elderly patients in multiple myeloma clinical trials. Oncologist. 2018;23(9):1076-1078.

15. Engelhardt M, Ihorst G, Singh M, et al. Real-world evaluation of health-related quality of life in patients with multiple myeloma from Germany. Clin Lymphoma Myeloma Leuk. 2021;21(2):e160-e175.

16. Kyle RA, Rajkumar SV. Criteria for diagnosis, staging, risk stratification and response assessment of multiple myeloma. Leukemia. 2009; 23(1):3-9.

17. Engelhardt M, Dold SM, Ihorst G, et al. Geriatric assessment in multiple myeloma patients: validation of the International Myeloma Working Group (IMWG) score and comparison with other common comorbidity scores. Haematologica. 2016;101(9):1110-1119. 